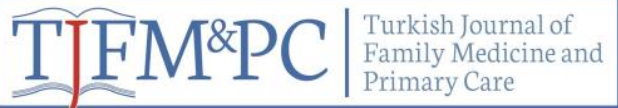

Original Research / Özgün Araştırma

\title{
How Does Telephone Consultation Effect Immunization Rates of the Elderly?
}

\author{
Yaşlılarda Bağışıklama Oranını Telefonla Bilgilendirme Nasıl \\ Etkiliyor?
}

Güzel Dişcigil $^{* 1}$, Büşra Korkmaz ${ }^{1}$

\begin{abstract}
Aim:We aimed to determine the immunization rates of the elderly in a family medicine out-patient clinic and effect of telephone consultation on immunization rates. Material and Method: A questionnaire was applied by telephone to four hundred patients over sixty years of age who were registered patients of a family medicine out- patient clinic between January 2010- May 2014. After the survey the patients were informed about elderly vaccination. The same patients were called and questioned about their vaccination status after three months. Results: Of the 400 patients 279 (\%69.8) were female, 121 (\%30.3) were male. Most of the participants stated that lack of knowledge was the reason of not having required immunization. Total immunized patients were $10(\% 2.5)$ during first call where as it was increased to $43(\% 10.8)$ after 3 months. Immunization rates were higher among elderly under 70 years of age after telephone consultation. Conclusion:Our results show that lack of knowledge is an important obstacle for immunization among elderly. Telephone consultation intervention helps to increase immunization rates especially among elderly under 70 years of age.
\end{abstract}

Key words: Elderly, vaccine, preventive medicine, intervention

\section{ÖZET}

Amaç: Bu çalışmada, aile hekimliği polikliniğine kayıtlı yaşlı bireylerin, aşılanma durumlarının saptanması ve telefonla bilgilendirme sonrası meydana gelen değişikliğin ortaya konması amaçlanmıştır. Gereç ve Yöntem: Ocak 2010-Mayıs 2014 yılları arasında, aile hekimliği polikliniği’ne kayıtlı 60 yaş ve üzeri hastalardan, toplam 400 kişiye telefonla görüşme yoluyla anket çalışması uygulanmıştır. Sonrasında, yaşlılık dönemi aşıları hakkında kısa bilgilendirme yapılmıştır. Aynı hastalar üç ay sonra aranarak, aşılanma durumları tekrar sorulmuştur. Bulgular: Çalışmaya, 279 (\%69,8)'u kadın, 121 (\%30,3)'i erkek, toplam 400 kişi katılmıştır. Katılımcıların önemli bir kısmı bilmedikleri için aşı olmadıklarını belirtmiştir. Bilgilendirme öncesi toplam aşılanan $10(\% 2,5)$ kişi iken, bilgilendirme sonrasında bu sayı $43(\% 10,8)$ kişiye çıkmıştır. Bilgilendirme sonrası 70 yaşın altındaki katılımcılarda aşılanma oranı, daha ileri yaş grubuna göre daha fazla bulunmuştur. Sonuç: Sonuçlarımız, bilgi eksikliğinin ileri yaş aşılaması açısından önemli bir engel olduğunu göstermektedir. Telefonla uygulanan standardize edilmiş bir bilgilendirme girişimi, özellikle 70 yaşın altındaki bireylerde aşılanma oranlarının artmasına yardımcı olmuştur.

Anahtar kelimeler: Yaşlı, aşı, koruyucu hekimlik, müdahale

Received Date / Geliş tarihi: 28.06.2018, Accepted Date / Kabul tarihi: 27.07.2018

${ }^{1}$ Adnan Menderes Üniversitesi Tıp Fakültesi Aile Hekimliği AD. Aydın, TÜRKIYYE.

*Address for Correspondence / Yazışma Adresi: Guzel Discigil, Adnan Menderes Üniversitesi Tıp Fakültesi Aile Hekimliği AD. Aydın,TÜRKIYE.E-mail:gdiscigil@gmail.com

Dişcigil G, Korkmaz B. Yaşlılarda Bağışıklama Oranını Telefonla Bilgilendirme Nasıl Etkiliyor? TJFMPC, 2019;13(1): 8-13.

DOI: 10.21763/tjfmpc.527949 


\section{GíRiş}

Dünyada ve ülkemizde giderek artan nüfus oranına sahip olan yaşlılar için planlanan sağlık hizmetleri; hastalıkların tanınması ve yönetimini sağlamanın yanı sıra, sağlığın korunması ve geliştirilmesini de içerir. Bağışıklama, koruyucu yaklaşımlar içinde çok önemli bir yere sahiptir. Yaşlı nüfusa sunulan bağışıklama hizmetleri, hem fiziksel ve bilişsel işlevsellik açısından, bağımsız bir toplum yapısına katkıda bulunacağ mali yükü ortadan kaldıracağı için, en az genç nüfusta olduğu kadar önemlidir. Yaşlılarda, hedeflenen grupların çok azının aşılanabildiği bildirilmektedir. ${ }^{1}$ Oysa yaşlılık döneminde de, çocukluk döneminde olduğu gibi aşılar bireyleri hastalıklardan korur ve ekonomik kayıpların yaşanmasını engeller. Günümüzde halen yaşlı bireyler, aşı ile önlenebilir hastalıklardan ölebilmektedir. Ancak çeşitli nedenlerle aşılama bu dönemde yeterince bilinmemekte veya önemsenmemektedir. Bu konuda bilgilendirme ve duyarlılığın arttırılmasına yönelik çalışmalara ihtiyaç vardir.

Bulaşıcı hastalıklardan ölümlerin engellenmesinde en etkili yöntemin,hastalık geliştikten sonra antibiyotik ile tedavinin değil, koruyucu olarak bağışıklamanın olduğu bilinmektedir. İlk aşı olarak bilinen çiçek aşısından itibaren, pek çok bulaşıcı hastalık, aşılar ile kontrol altına alınmıştır. ${ }^{2}$

Erişkin aşılama programı kapsamında, birçok ülkenin aşılama kılavuzları mevcuttur. Ülkemizde de yaşlılık döneminde, pnömokok, tetanoz ve y1llı influenza aşısı önerilmektedir. ${ }^{1}$ Ayrıca, zona aşısı da yakın zamanda öneriler arasında yer almaya başlamıştır. ${ }^{1}$

Yaşl1lık döneminde önerilen aşılardan biri olan influenza aşısı ile yaşlılarda ölümcül seyredebilen influenzadan önemli oranda korunmak mümkündür.1500'lü yıllardan beri, pandemilere neden olan influenzanın "İspanyol gribi” olarak ta bilinen 1918'deki pandemisinde dünya genelinde 21 milyon kişi hayatını kaybetmiştir. ${ }^{3}$ Günümüzde de halen influenza mevsiminde, her yıl hastane başvuru ve yatışları artmakta, işgücü kaybı yaşanmakta, çocuk, yaşlı, kronik hastalığı veya immün yetmezliği olanlar için ölümcül seyirli durumlar görülmektedir. Oysa bağışıklama ile hastane yatış oranlarında ve ölüm riskinde önemli oranda azalma sağlanabilmektedir. ${ }^{4}$
Pnömokok, ilk kez 1881 yılında Pasteur tarafından tanımlanmıştır. Penisilinin keşfiyle, aşı çalışmaları bir süre duraksamış olsa da, hastalığın mortal seyri nedeniyle tekrar canlanmıştır. İlk pnömokok aşısı 1977 yılında, ilk konjuge pnömokok aşısı ise 2000 yılında lisans almıştır. ${ }^{4}$ Yaşlılarda, pnömokok ve influenza aşısının her ikisinin de yapılmış olmasının hem grip, hem de pnömoniye bağlı hastaneye yatışlarını ve mortaliteyi önemli oranda azalttı̆̆ı gösterilmiştir. ${ }^{5}$

Tetanoz, çocukluk çağı aşılarından biri olmasına rağmen, erişkinlerin tetanoza karşı immünizasyonun yetersiz olduğu belirtilmektedir. Bu nedenle, yaşlılarda tetanoz ve tetanoza bağlı ölüm riskinin yüksek olduğu vurgulanmakta, her yıl bir milyondan fazla tetanoz vakasının görüldüğü bildirilmektedir. ${ }^{4}$ Difteri ve tetanoz toksoidlerinin primer serisini tamamlamış erişkinlerin, her 10 yılda bir aşılarının tekrarlanması hastalıktan korunmada en etkili yoldur. ${ }^{4}$

Aile hekimleri, bakımın sürekliliği açısından sağlı̆̆ı korunması ve geliştirilmesinde en etkili hekim grubu olarak görülebilir. Yaşlı sağlığı açısından ise bağışıklamanın izlemi ve öneminin anlaşılması açısından önemli bir rol üstlenmektedir. $\mathrm{Bu}$ doğrultuda araştırmamızda, aile hekimliği polikliniğimize kayıtlı yaşlı bireylerin aşılanma durumlarını saptamayı ve bilgilendirme sonrası durum değişikliğini, yani bilgilendirme müdahalesinin etkinliğinin ortaya konması amaçlanmıştır.

\section{GEREÇ VE YÖNTEM}

Araştırma, primer korunmaya yönelik müdahale araştırması olarak planlanmıştır.Etik kurul ve kurum onayları alındiktan sonra, Adnan Menderes Üniversitesi Tip Fakültesi (ADÜ) Aile Hekimliği polikliniği'ne, Ocak 2010 ve Mayıs 2014 arasında kayıtlı olan 60 yaş ve üzeri kişilerin iletişim bilgilerine ulaşılmıştır. Toplam 468 kişinin kayıdına ulaşılmıştır. 68 Kişiye çeşitli nedenlerle ulaşılamamış ve çalışma 400 kişi ile tamamlanmıştır.

Katılımcılara, influenza aşısını kapsamak amaciyla sonbahar döneminde telefonla ulaşılarak pnömokok, influenza ve tetanoz aşılarının uygun zaman ve aralıkta uygulanma durumları sorulmuştur. Ardından ileri yaşta bağışıklama ile ilgili standardize edilmiş bilgilendirme yapılmıştır. Üç ay sonra, tekrar aşılanma durumlarını öğrenmek üzere aranacakları bilgisi verilerek görüşme 
tamamlanmıştır. Üç ay sonra tekrar aranarak, aşılanma durumları sorulmuş ve kaydedilmiştir.

Verilerin analizinde, ortalama, ortanca, standart sapma, dağılım aralığı ve yüzdeler gibi tanımlayıc1 istatistikler, kategorik değişkenler arası karşılaştırmalarda ki-kare testi, bilgilendirme öncesi ve sonrası aşılanma oranları arasındaki farkın anlamlılık düzeyini ölçmek için McNemar testi kullanılmıştır. Bağımsız değişkenler ile bağımlı değişken arasındaki ilişkinin belirlenmesi için, tekli analizler (univariateanalysis) ve bağımsız değişkenlerin bağımlı değişken üzerine etki derecesini belirlemek için çoklu lojistik regresyon analizi (multiple logistic regression analysis) yapılmıştır.

\section{BULGULAR}

Çalışmaya, 279'u (\%69,8) kadın, 121'i $(\% 30,3)$ erkek, toplam 400 kişi katılmış olup; yaş ortalamaları 70,6 \pm 7,8 yıldı (60-93 yaş). Kadınların yaş ortalaması 70,6 \pm 7,6 yıl (60-92 yaş) ve erkeklerin yaş ortalaması 70,8 $\pm 8,3$ yıl (60-93 yaş) olarak bulunmuştur. Ayrıca çalışmaya katılan 400 kişiden, 248'inin (\%62) herhangi bir kronik bir hastalığı mevcuttu. Sadece $10(\% 2,5)$ kişi daha önce yaşlılık dönemi aşılarından en az birini yaptırmıştır. Üç aşının tamamını yaptıran hiç bir katılımeı saptanmamıştır. Aşı yaptırmama nedeni olarak,
241(60,9) kişi bilmediği için yaptırmamış olduğunu belirtmiştir. Bilgilendirmeden 3 ay sonra, aşı yaptıranların sayısı 43 'e( $\%$ 10,8) yükselmiştir. Bilgilendirme sonrası en az bir aş1 yaptıranlar, bilgilendirme öncesi en az bir aşı yaptıranlara göre anlamlı ölçüde daha fazla bulunmuştur $(p=0,000)$.

Bağımsız değişkenlerin (demografik veriler), bağıml değişken (yaşlıların bilgilendirme sonrası influenza, pnömokok ve tetanoz aşısı yaptırma durumu) ile ilişkisi tekli analizlerle (univariate analysis) değerlendirilmiştir. Yaş, medeni durum, ögrrenim durumu ve kronik hastalık ile aşı yaptırma arasında anlamlılık saptanmıştır. Ardından anlamlı bulunan bu bağımsız değişkenlerin, yaşlı bireylerin aşıları yaptırma davranışı üzerine etkisini belirlemek için çoklu lojistik regresyon analizi yapılmıştır. Buna göre, her üç aşı için yalnızca yaş değişkenin anlamlı sonuca ulaştığı görülmüştür. 70 yaş ve üzerindekiler, referans alındığında 70 yaşın altındaki yaşlıların influenza aşısını 6,9 kat, pnömokok aşısını $11,1 \mathrm{~kat}$ ve tetanoz aşısını 11,4 kat daha yüksek oranda yaptırdığı saptanmıştır.

Yaşlı bireylerin, influenza, pnömokok ve tetanoz aşılarını yaptırma davranışı üzerine etki eden faktörleri içeren çoklu lojistik regresyon analizi sonuçları sırasıyla Tablo1, 2 ve 3 'te gösterilmiştir.

\begin{tabular}{|c|c|c|c|c|c|c|}
\hline \multicolumn{7}{|c|}{$\begin{array}{l}\text { Tablo 1. Yaşlı bireylerin influenza aşısı yaptırma c } \\
\text { çoklu lojistik regresyon modeli sonuç tablosu } \\
\text { Bağımlı değişken: Yaşlı bireylerin influenza aşısı yaptırma davranışı }\end{array}$} \\
\hline \multicolumn{2}{|c|}{ Modeldeki bağımsız değişkenler } & Beta & Standart & $\mathbf{p}$ & Oddsratio & \%95 güven aralığı \\
\hline \multirow[t]{2}{*}{ Yaş } & $\begin{array}{l}70 \text { yaşın altındaki } \\
\text { yaşlılar }\end{array}$ & 1,936 & 653 & ,003 & 6,930 & $1,925-24,941$ \\
\hline & $\begin{array}{l}70 \text { yaş ve üzerindeki } \\
\text { yaşlilar }\end{array}$ & & & & 1 (referans) & \\
\hline \multirow{2}{*}{ Medeni durum } & Evli olanlar & ,631 &, 457 & 167 & 1,880 & ,768-4,601 \\
\hline & Evli olmayanlar & & & & 1 (referans) & \\
\hline \multirow[t]{2}{*}{ Eğitim durumu } & Eğitim almış & ,371 & ,673 & ,582 & 1,449 & ,387-5,425 \\
\hline & $\begin{array}{l}\text { Hiç okula gitmemiş } \\
\text { olanlar }\end{array}$ & & & & 1 (referans) & \\
\hline \multirow[t]{2}{*}{ Kronik hastalık } & $\begin{array}{l}\text { Kronik hastalığ } 1 \\
\text { olmayanlar }\end{array}$ & ,446 & ,415 & 282 & 1,563 & ,693-3,523 \\
\hline & $\begin{array}{l}\text { En az bir kronik } \\
\text { hastalığı olanlar }\end{array}$ & & & & 1 (referans) & \\
\hline Sabit & & $-4,188$ & ,797 & ,000 & ,0015 & \\
\hline
\end{tabular}




\begin{tabular}{|c|c|c|c|c|c|c|}
\hline Bağımlı değişke & Yaşlı bireylerin pnöm & aşısı yap & a davranışı & & & \\
\hline Modeldeki bağı & sız değişkenler & Beta & Standart & $\mathbf{p}$ & Oddsratio & \%95 güven aralığı \\
\hline Yaş & $\begin{array}{l}70 \text { yaşın altındaki } \\
\text { yaşılıar }\end{array}$ & 2,403 & ,761 & ,002 & 11,055 & $2,487-49,127$ \\
\hline & $\begin{array}{l}70 \text { yaş ve üzerindeki } \\
\text { yaşlılar }\end{array}$ & & & & 1 (referans) & \\
\hline Medeni durum & Evli olanlar & ,773 & ,489 & ,114 & 2,167 & ,831-5,654 \\
\hline & Evli olmayanlar & & & & 1 (referans) & \\
\hline Öğrenim & Eğitim almış & ,358 & ,744 & 630 & 1,431 & $, 337-6,146$ \\
\hline durumu & $\begin{array}{l}\text { Hiç okula gitmemiş } \\
\text { olanlar }\end{array}$ & & & & 1 (referans) & \\
\hline Kronik hastalık & $\begin{array}{l}\text { Kronik hastalığ } \\
\text { olmayanlar }\end{array}$ & 465 & ,417 & 264 & 1,593 & ,703-3,608 \\
\hline & $\begin{array}{l}\text { En az bir kronik } \\
\text { hastalığ1 olanlar }\end{array}$ & & & & 1 (referans) & \\
\hline Sabit & & $-4,785$ &, 899 & ,000 & ,008 & \\
\hline
\end{tabular}

\begin{tabular}{|c|c|c|c|c|c|c|}
\hline \multicolumn{7}{|c|}{ Bağımlı değişken: Yaşlı bireylerin tetanoz aşısı yaptırma davranışı } \\
\hline \multicolumn{2}{|c|}{ Modeldeki bağımsız değişkenler } & Beta & $\begin{array}{l}\text { Standart } \\
\text { hata }\end{array}$ & $\mathbf{p}$ & Oddsratio & $\% 95$ güven aralığı \\
\hline \multirow[t]{2}{*}{ Yaş } & $\begin{array}{l}70 \text { yaşın altındaki } \\
\text { yaşlılar }\end{array}$ & 2,432 & 761 & ,001 & 11,381 & $2,559-50,625$ \\
\hline & $\begin{array}{l}70 \text { yaş ve üzerindeki } \\
\text { yaşlılar }\end{array}$ & & & & 1 (referans) & \\
\hline \multirow[t]{2}{*}{ Medeni durum } & Evli olanlar & ,746 & ,491 &, 129 & 2,109 & $805-5,521$ \\
\hline & Evli olmayanlar & & & & 1 (referans) & \\
\hline \multirow{2}{*}{$\begin{array}{l}\text { Öğrenim } \\
\text { durumu }\end{array}$} & Eğitim almış & 320 & ,745 & 667 & 1,378 & ,320-5,935 \\
\hline & $\begin{array}{l}\text { Hiç okula gitmemiş } \\
\text { olanlar }\end{array}$ & & & & 1 (referans) & \\
\hline \multirow[t]{2}{*}{ Kronik hastalık } & $\begin{array}{l}\text { Kronik hastalığ } \\
\text { olmayanlar }\end{array}$ & 507 & ,419 & 226 & 1,660 & ,730 -3,776 \\
\hline & $\begin{array}{l}\text { En az bir kronik } \\
\text { hastalığı olanlar }\end{array}$ & & & & 1 (referans) & \\
\hline Sabit & & $-4,765$ & ,900 & ,000 & ,009 & \\
\hline
\end{tabular}

\section{TARTISMA}

Yaşlı bireylerin aşılanma durumu ve bilgilendirmenin aşılanma durumuna etkisini değerlendirmeyi amaçlayan çalışmamızın öne çıkan bulguları; aşılanma oranının düşük olması, bilgilendirme sonrası aşılanmada artış olması, daha genç yaş grubunda olan bireylerin bilgilendirmeden en fazla yararlanan grup olması, kronik hastalık varlığının aşılanma durumuna etkisiz olması olarak saptanmıştır.

Çalışmamızda, bilgi eksikliği nedeniyle aşı yaptırmadığını bildiren katılımcı oranı oldukça yüksek bulunmuştur. Bu konuda literatürdeki veriler çeşitlilik göstermektedir. Uluslararası bir çalışmada, bireylerin \%96'sı influenza, \%90'1 tetanoz ve $\% 65$ 'i pnömokok aşıları hakkında bilgi sahibi olduğu belirtilmiştir. ${ }^{6}$ Ülkemizde, İstanbul'da yapılan bir başka çalışmada ise, tetanoz aşısı uygulanma zamanını bilen \%4,6 iken, pnömokok aşısı uygulanma zamanını bilen $\% 4,1$ ve influenza aşısı uygulanma zamanını bilen kişi oranı \%100 olarak bildirilmiştir. ${ }^{7}$ Ulusal çalışmalara bir başka örnek olarak Ankara'da yapılan bir çalışmada; katılımcılardan hiçbirinin tetanoz ve pnömokok aşılarının kendi yaş grubuna uygulanması ile ilgili bilgileri yokken, influenza aşısı hakkında doğru ve tam bilgiye sahip olanlar çalışma grubunun \%25'ini oluşturduğu belirtilmiştir. ${ }^{8}$

Çalışmamızda, toplam aşılanma düzeyinin $\% 2,5$ gibi oldukça düşük bir oranda olduğunu görülmüştür. Bizim çalışmamıza benzer olarak, 65 yaş ve üzerinde aşılanma düzeyini düşük belirleyen ulusal ve uluslararası birçok çalışma mevcuttur. Bu çalışmalarda, aşılanma oranları \%3 ile \%28 arasında değişmektedir. ${ }^{7,8,9}$ 
Çalışmamızda, bilgilendirme sonrası toplam aşılanma oranı \%10,8'e çıkmaktadır. Bilgilendirme sonrasında, öncesine göre oranın yükselmesi, haberdar olma ve farkındalığın önemini ortaya koymaktadır.

Kronik hastalık varlı̆̆ının, aşılanmayı etkilememesi dikkat çekici bir bulgu olarak karşımıza çıkmaktadır. Bizim çalışmamıza benzer olarak ulusal iki çalışmada, kronik hastalık varlığının aşılanmayı pozitif olarak etkilemediği bildirilmektedir. ${ }^{7,10} \mathrm{Bu}$ durum, bağışıklamanın çok daha fazla önem arz ettiği kronik hastalığı olan yaşlıların, aşıyla önlenebilir enfeksiyon hastalıklarından yeterince korunamadığını düşündürmektedir. Kronik hastalıkların yönetiminde genellikle acil durumların bakım sürecine hakim olduğu bilinmektedir. ${ }^{11} \mathrm{Bu} \quad$ nedenle, kronik hastalıkların yönetim sürecinde bağışıklama gibi koruyucu önlemlerin görüşmeye dahil edilmesi, akut durumların yönetiminin yanında koruyucu sağlık hizmetlerinin sunulması, genel sağll $\breve{g ̆}_{1}$ iyileştirici ve geliştirici bir yaklaşım olacaktır.

Çalışmamıza katılan bireylerden, bilmedikleri için aşı yaptırmayanların oranının yüksek olduğu gözlenmektedir. Yapılan çalışmalar, aşı oranlarının düşük olmasında, kişilerin aşılar hakkındaki bilgi düzeylerinin yetersiz olmasının etkili olabileceğine dikkat çekmektedir. Bu konuda yapılan uluslararası bir çalışmada; infuenza ve pnömokok aşısı için, doktoru önerdiği takdirde yaptıracağ1 yönünde bildirimlerin oranı oldukça yüksek bulunmuştur. ${ }^{12}$ Pnömokok aş1lanmasının önündeki hasta ve hekimlerle ilgili engelleri inceleyen bir çalışmada ise, aşılanmamış olan bireylerin çoğunun aşının yararları hakkında bilgi sahibi olmadığı belirtilmiștir. ${ }^{13}$ Yine, pnömokok aşılaması ile ilgili yapılan bir başka çalışmada; aşıyla ilgili broşür verilen bireylerin, yaklaşık dört kat daha fazla oranda doktorları ile aşılanma hakkında görüştükleri ve yaklaşık beş kat daha fazla oranda aşılandıkları belirtilmektedir. ${ }^{14}$ Hasta bekleme odasına, kolay anlaşılır materyaller konması, hastane acillerinde veya hastaneden çıkış öncesi aşılama önerilmesi, hasta-hekim eğitimi, aşı hatırlatma sistemi ve aşı rehberlerinin hazırlanması maliyet etkin yöntemler olarak bildirilmektedir. ${ }^{13}$ Aşılamanın hatırlatılması, aşılanma oranlarını artırmakta ve bilgilendirme etkisinin önemini ortaya koymaktadır. Bu konuda, 11 ülkeyi kapsayan bir çalışmada, "İnfluenzanın ciddi bir hastalık olduğunun farkında olmak" çalışması katılan ülkelerde aşılanma oranını artırmıştır. Aile hekiminin önerisi, aşılanma yönünde bireyi cesaretlendiren en önemli faktör olarak belirtilmiştir. Ayrıca, "diğer aile bireylerine hastalığ1 bulaştırmayı istememek" aşılanma oranlarını artıran bir faktör olarak tanımlanmıştır. Aşılanmama nedenlerine bakıldığında ise en büyük engel aşılanmanın farkında olmamaktır. ${ }^{15} \mathrm{Bu}$ doğrultuda yaşlılara yönelik farkındalık sağlayacak aşı kampanyalarında, influenza ve pnömoni hastalıklarının şiddeti, riskleri ve semptomları üzerinde durulması önerilmektedir. ${ }^{16}$ Aile hekiminin, bağışıklamanın kazandırdıklarının vurgulanması yönündeki önerisinin etkisi çalışmalarla desteklenmektedir. ${ }^{17}$

Çalışmamızın sonuçları, telefonla bilgilendirmenin ileri yaşta aşılanma oranlarını arttırdığını göstermektedir. Aile hekimlerinin bu konudaki duyarlılıklarının artması,ileri yaş grubundaki hastaların bu açıdan izlenmeleri ve bilgilendirilmeleri koruyucu sağlık hizmetlerine büyük katkı sağlayacaktır.

\section{KAYNAKLAR}

1. Erişkin Bağışıklama Rehberi. Türkiye Enfeksiyon Hastalıkları ve Klinik Mikrobiyoloji Uzmanlık Derneği Erişkin Bağışıklama Rehberi Çalışma Grubu. 2009. http://ekmud.org.tr/calisma-grubu/4bagisiklama-calisma-grubu Erişim tarihi: 07.06.2018.

2. Selçuk E. Aşıların tarihçesi. Türkiye Klinikleri J FamMed-Special Topics 2011;2(5): 1-4.

3. Keech M, Beardsworth P. Theimpact of influenza on workingdayslost: a review of theliterature. Pharmacoeconomics 2008; 26(11): 911-24.

4. 4.Atkinson W, Wolfe S, Hamborsky J. CentersforDisease Control andPrevention. EpidemiologyandPrevention of Vaccine PreventableDiseases. 13.th ed. Washington DC: Public Health Foundation 2015: 187-350.

5. Arinez-Fernandez MC, Carrasco-Garrido P, Gil de Miguel A, Jimenez-Garcia R. Influenzaandpneumococcalvaccination in chronicobstructivepulmonarydisesae(COP D). Respmed:COPDupdate 2007; 3: 95101.

6. Johnson D.R, Nichol K.L, Lipczynski K. Barrierstoadultimmunization.

TheAmericanJournal Of Medicine2008; 121: 28-35.

7. Akman M, Sarısoy M, Uzuner A. Altmıs beş yaş üstü erişkinlerde aşılanma durumu ve bilgi düzeyleri. TurkishFamilyPhsysician 2014; 5(3);1923. 
8. Zeybek Y, Tokalak İ, Boyacıŏlu S. Altmış beş yaş ve üzeri erişkinlerde aşılanma durumu. Türk Geriatri Dergisi 2004; 7 (3): 152-154.

9. Smorenburg AJ, Oostermana BJ, Grobbea DE, Bonten MJ, Roes KC. Effects of recruitmentstrategiesanddemographicfacto rs on inclusion in a largescalevaccinationtrial in adults 65 yearsandolder. A.J. Vaccine 2014; 32: 2989-94.

10. Özsu S, Ergün U, Arslan Y, Maden E, Bilgiç H. Thefrequency of influenzaandpneumococcalvaccination in COPD. Solunum Derg 2011; 13(1): 2125.

11. Moore LG. Escapingthetyranny of theurgentbydeliveringplannedcare.

FamPract Manag 2006;13(5):37-40.

12. Nichol K.L, Mac Donald R, Hauge M, Factorsassociatedwithınfluenzaandpneum ococcalvaccinationbehavioramonghighrisk adults. TheJournal of General InternalMedicine1996;11: 673-77.

13. Mieczkowski T.A, Wilson S.A. Adultpneumococcalvaccination: a review of physicianpatientbarriers. Vaccine2002;20: 1383-92.

14. Jacobson T.A, Thomas D.M, Morton F.J, OffutGardnier, Shevlin S, Ray S. Use of a low-

literacypatienteducationtooltoenhancepneu mococcalvaccinationrates. TheJournal of AmericanMedicalAssociation 1999; 282(7): 646-50.

15. BlankP.R, Schwenkglenks M, SzucsT.D. Vaccinationcoveragerates in eleveneuropeancountriesduringtwoconsec utiveinfluenzaseasons. Journal of İnfection. 2009;58: 446-58.

16. Santibanez TA, Nowalk MP, Zimmerman RK. Knowledge andbeliefsaboutinfluenza, pneumococcaldisease, andimmunizationsamongolderpeople.JAm Geriatr Soc2002;50(10):1711-16.

17. Szucs T.D, Müller D. Influenzavaccinationcoveragerates in fiveeuropeancountries- a populationbasedcross- sectionalanalysis of twoconsecutiveinfluenzaseasons. Vaccine. 2005;23: 5055-63. 